\title{
The Missing Link: The Use of Link Words and Phrases as a Link to Manuscript Quality
}

\author{
Anthony J. Onwuegbuzie (Corresponding author) \\ Department of Educational Leadership and Counseling, Sam Houston State University \\ Box 2119, Huntsville, Texas 77341-2119, USA \\ $\&$ \\ Distinguished Visiting Professor, Faculty of Education, University of Johannesburg \\ B-Ring 433, Kingsway Campus, Auckland Park, South Africa \\ E-mail: tonyonwuegbuzie@aol.com
}

Received: July 4, 2016 Accepted: December 4, 2016 Published: December 5, 2016

doi:10.5296/jei.v2i2.9697ＵRL: http://dx.doi.org/10.5296/jei.v2i2.9697

\begin{abstract}
In this article, I provide a typology of transition words/phrases. This typology comprises 12 dimensions of link words/phrases that capture 277 link words/phrases. Using QDA Miner, WordStat, and SPSS - a computer-assisted mixed methods data analysis software, content analysis software, and statistical software, respectively-I analyzed 74 manuscripts that were submitted to the journal Research in the Schools over a 2-year period (i.e., 2014-2015). Among other results, these analyses revealed the most common link words/phrases and the most common dimensions of link words/phrases, as well as the dimensions that best predicted whether or not a manuscript was rejected by the editor.
\end{abstract}

Keywords: Link words, Link phrases, Transition words, Research in the Schools, Writing with discipline, Manuscript rejection, Manuscript acceptance

\section{Introduction}

Over the last few years, Onwuegbuzie and colleagues have written a series of works (e.g., articles, book chapters, book) in which they have demonstrated the importance of writing with discipline when writing dissertations and preparing scholarly works for consideration for publication in journals. In particular, these authors have established the importance of avoiding violations to the American Psychological Association (APA) style guide (APA, 2010) regarding the following components of a manuscript: 
> Abstract (Hahs-Vaughn, Onwuegbuzie, Slate, \& Frels, 2009);

$>$ Body of the manuscript (Onwuegbuzie, Combs, Slate, \& Frels, 2010);

$>$ Reference list (Onwuegbuzie, Combs, Frels, \& Slate, 2011; Onwuegbuzie, Frels, \& Slate, 2010; Onwuegbuzie, Hwang, Combs, \& Slate, 2012; Onwuegbuzie, Hwang, Frels, \& Slate, 2011);

\section{$>$ Table (Frels, Onwuegbuzie, \& Slate, 2010).}

Most recently, Onwuegbuzie, Mallette, Hwang and Slate (2013) provided evidence that the readability of the manuscript is an important predictor of the quality of a manuscript. Specifically, using the Flesch Reading Ease (RE) and Flesch-Kincaid Grade Level (GL) - two popularized and easily accessible readability formulas - among other findings, Onwuegbuzie et al. (2013) documented that (a) manuscripts with Flesch RE scores between 0 and 30 were 1.64 more times less likely to be rejected than were manuscripts with Flesch RE scores greater than 30, and (b) manuscripts with Flesch-Kincaid GL scores of 16 and above were 4.55 times less likely to be rejected than were manuscripts with Flesch-Kincaid GL scores less than 16. According to these researchers, these findings indicate that "specialized, technical, difficult, and dense text draws more favorable reviews, and is more likely to be accepted for publication, than is text with lower readability estimates" (pp. ix-x) and that "when authors disseminate their work, by crafting text that is equally thoughtful and rigorous, it is well received by consumers" (p. x).

Simply put, findings from these series of works have demonstrated that authors are statistically and practically significantly more likely to have their manuscripts rejected for publication if they do not write with discipline. However, adhering to APA style in various sections of a manuscript and to readability guidelines are not the only pathways to writing with discipline. In fact, when writing with discipline, I contend that it is also advantageous for authors to use link words and phrases. Indeed, as an editor-in-chief of a journal (i.e., International Journal of Multiple Research Approaches), past editor of a journal (i.e., Educational Researcher), current editor of a journal (i.e., Research in the Schools), and guest editor of several special issues (e.g., International Journal of Qualitative Methods, International Journal of Multiple Research Approaches) - totaling more than 20 years as an editor-as well as serving as a reviewer for more than 20 journals, I have noticed that a common weakness of manuscripts written by beginning writers - and even more experienced writers - is the lack of appropriate transitions between sentences and between paragraphs. Unfortunately, this lack of transitions prevents a manuscript from being maximally coherent, thereby making it more difficult for readers in general and journal reviewers in particular to follow the author's logic of argumentation. Link words/phrases are very useful for connecting ideas and, hence, for connecting sentences and paragraphs. However, to date, no researcher formally has examined the either the use or effect of link words/phrases.

\subsection{Purpose of Study}

With the aforementioned discussion in mind, the purpose of my study was to examine the prevalence of link words/phrases in manuscripts submitted to a journal for consideration for 
publication. A second purpose was to examine the importance of link words/phrases on the quality of empirical manuscripts submitted to a journal for consideration for publication, as indicated by their eventual disposition (i.e., accept/revise and resubmit vs. reject). Specifically, the thoroughness of the inquiry led to the following five research questions being addressed:

1) What is the prevalence of link words/phrases among manuscripts submitted to the Research in the Schools journal?

2) What is the relationship between the frequency of link words/phrases and style guide errors (i.e., APA errors) among manuscripts submitted to the Research in the Schools journal?

3) What is the relationship between the frequency of link words/phrases and citation errors among manuscripts submitted to the Research in the Schools journal?

4) What is the relationship between the frequency of link words/phrases and select demographic characteristics (i.e., number of authors, gender of the lead author, genre of manuscript) among manuscripts submitted to the Research in the Schools journal?

5) What is the relationship between the frequency of link words/phrases and manuscript disposition among manuscripts submitted to the Research in the Schools journal?

\subsection{Conceptual Framework}

Onwuegbuzie and Frels (2016) identified a typology of transition words and phrases. Specifically, their typology comprises the following 12 dimensions of link words/phrases:

$>$ Add information/provide similarity (e.g., Further; Moreover)

$>$ Narration (e.g., Initially; Suddenly)

$>$ Provide an emphasis (e.g., Specifically; Particularly)

$>$ Contrast ideas (e.g., However; Although)

$>$ Summarize previous information (e.g., In summary; In other words)

$>$ Provide a result (e.g., Therefore; Consequently)

$>$ Express purpose (e.g., With this in mind; To this end)

$>$ Sequence previous ideas (e.g., First; The former)

$>$ Provide a reason (e.g., Because; Inasmuch as)

$>$ Space/location/place (e.g., Alongside; Wherever)

$>$ Time (e.g., Presently; Meanwhile)

$>$ Provide examples (e.g., For instance; As an example).

These dimensions capture at least 277 link words/phrases. Although this list of link words is not exhaustive, it is extremely comprehensive-containing the most popular link words used 
in the English language. These link words are presented in Chapter 11 (i.e., p. 337) of Onwuegbuzie and Frels's (2016) textbook.

\section{Method}

\subsection{Sample Size and Procedures}

To analyze the prevalence and predictability of link words/phrases among manuscripts submitted to a journal, I examined 74 manuscripts submitted to Research in the Schools (RITS) over a 2-year period (i.e., 2014-2015). These manuscripts represented approximately $50 \%$ of all manuscripts submitted to this journal over this time frame, which made these findings generalizable at the very least to the population of manuscripts submitted to RITS. The sample size of 74 was selected via an a priori statistical power analysis. Specifically, it represented the sample size needed to detect a moderate multivariate relationship (i.e., discriminant analysis; $f=.28$ ) simultaneously for 12 dependent measures (i.e., 12 dimensions of link words/phrases) between the two groups (i.e., manuscripts that were rejected vs. manuscripts that were not rejected) at the $5 \%$ level of statistical significance and a power of .80 .

For each of the 74 manuscripts submitted to Research in the Schools over this time period, I meticulously documented every APA error and citation error committed by these 74 sets of authors. Each manuscript took up to 4 hours to identify all the APA errors and citation errors-representing as much as 296 hours of coding. In addition, I noted several demographic features of the manuscript (e.g., number of authors, gender of first author, genre of manuscript), as well as the disposition of the manuscript. Finally, I used QDA Miner, Version 4.1.12 (Provalis Research, 2014a) to conduct an initial coding of the 74 manuscripts for the link words/phrases contained in them, as well as to code characteristics of each manuscript (e.g., genre of manuscript [i.e., qualitative vs. quantitative vs. mixed methods vs. non-empirical]; number of authors, page length, word count); Microsoft Excel 2016 to create a spreadsheet that contained Onwuegbuzie and Frels's (2016) 277 link words/phrases; WordStat 6.1.23 (Provalis Research, 2014b) to import the 277 link words/phrases from the Microsoft Excel 2016 database and to conduct an a priori quantitative content analysis that determined the prevalence rates; and SPSS to conduct a discriminant analysis to determine the predictability of the dimensions of link words/phrases with respect to manuscript disposition (i.e., reject vs. non-reject [i.e., accept, revise and resubmit]) among manuscripts submitted to RITS. As such, the data set created was extremely rich.

\subsection{Analysis}

Descriptive statistics (i.e., measures of central tendency) were used to address the first research question (i.e., What is the prevalence of link words/phrases among manuscripts submitted to a journal?). In particular, frequency counts and percentages were computed for each of the 12 dimensions of link words/phrases. Furthermore, a multiple regression analysis was conducted to determine, which dimensions of link words/phrases as a set, if any, predicted the number of APA errors committed (Research Question 2), the number of citation errors committed (Research Question 3), and demographic characteristics (i.e., number of 
authors) (Research Question 4). Finally, a discriminant analysis was used to determine which dimensions of link words/phrases as a set, if any, discriminated the gender of the lead author and genre of manuscript (Research Question 4) and the two sets of manuscripts (i.e., manuscripts that were rejected vs. manuscripts that were not rejected) (Research Question 5).

\section{Results}

\subsection{Research Question 1. What is the Prevalence of Link Words/Phrases among Manuscripts Submitted to a Journal?}

The dimension labelled as Add information/provide similarity was the most commonly used, with 156 overall uses of link words belonging to this dimension across 53 out of the 74 (71.6\%) manuscripts; this was followed by the dimension labelled narration, with 97 overall uses of link words belonging to this dimension across 45 out of the 74 (60.8\%) manuscripts; and then followed by the dimension labelled sequence previous ideas, with 85 overall uses of link words belonging to this dimension across 40 out of the $74(60.8 \%)$ manuscripts. The remaining nine dimensions were used in less than $50 \%$ of the manuscripts. The three most common link words, respectively, were Additionally (with 98 overall uses of link words belonging to this dimension across 38 out of the 74 [51.4\%] manuscripts), Finally (with 79 overall uses of link words belonging to this dimension across 39 out of the 74 [52.7\%] manuscripts), and Similarly (with 79 overall uses of link words belonging to this dimension across 39 out of the 74 [52.7\%] manuscripts). All other link words/phrases appeared in one third of the manuscripts or less.

\subsection{Research Question 2. What is the Relationship between the Frequency of Link} Words/Phrases and Style Guide Errors (i.e., APA Errors) among Manuscripts Submitted to a Journal?

An all possible subsets (APS) multiple regression analysis (Onwuegbuzie \& Daniel, 2003; Thompson, 1995) was used to identify an optimal combination of link words/phrases dimension variables (i.e., independent variables) that predicted the number of the APA errors. Using this technique, all possible models involving some or all of the independent variables were examined. This method of analysis has been recommended by many researchers (see, for e.g., Onwuegbuzie \& Daniel, 2003; Thompson, 1995). For this study, the criterion used was the maximum proportion of variance explained $\left(R^{2}\right)$, which provides an important measure of effect size (Cohen, 1988).

The APS multiple regression analysis revealed that a model containing one link words/phrases dimension provided the best fit $(F[1,72]=5.18, p<0.05)$ to the prediction of the number of APA errors, namely, narration. This variable explained $34.1 \%$ of the variation in the number of APA errors. Using Cohen's (1988) criteria for assessing the predictive power of a set of independent variables in a multiple regression model, the proportion of variance explained indicates a very large effect size, because it far exceeds the $26 \%$ cut-off point. An inspection of the studentized (i.e., standardized) residuals generated from the model (Myers, 1986) suggested that the assumptions of normality, linearity, and homoscedasticity were met. Using the Bonferroni adjustment, none of the studentized residuals suggested that any 
outliers were present. The regression model suggests that authors who use link words/phrases that can be classified as representing narration tended to make the least APA errors.

\subsection{Research Question 3. What is the Relationship between the Frequency of Link Words/Phrases and Citation Errors among Manuscripts Submitted to a Journal?}

A second APS multiple regression analysis revealed that no link words/phrases dimension predicted the number of citation errors. Thus, these findings indicate that the use of link words/phrases represents a very distinct construct from citation errors. As such, authors who minimally or do not use link words/phrases are not necessarily those authors who commit citation errors (Onwuegbuzie, Combs, et al., 2011; Onwuegbuzie, Frels, et al., 2010).

3.4 Research Question 4. What is the Relationship between the Frequency of Link Words/Phrases and Select Demographic Characteristics (i.e., Number of Authors, Gender of the Lead Author, Genre of Manuscript) among Manuscripts Submitted to a Journal?

A third APS multiple regression analysis revealed that a model containing one link words/phrases dimension provided the best fit $(F[1,72]=4.65, p<0.05)$ to the prediction of the number of authors, namely, summarize previous information. This variable explained $16.8 \%$ of the variation in the number of authors. The proportion of variance explained indicates a moderate effect size, because it lay between the range of $13 \%$ and $25.99 \%$. An inspection of the studentized (i.e., standardized) residuals generated from the model (Myers, 1986) suggested that the assumptions of normality, linearity, and homoscedasticity were met. Using the Bonferroni adjustment, none of the studentized residuals suggested that any outliers were present. The regression model suggests that manuscripts in which link words/phrases were used that can be classified as summarizing previous information tended to contain the most authors. In contrast, an all possible subsets canonical discriminant analysis revealed that no link word/phrase dimension statistically significantly $\left(\times^{2}[3]=12.74\right.$, $p=.24$; Wilks's Lambda $=0.62$ ) predicted either the gender of the first author or the genre of manuscript.

\subsection{Research Question 5. What is the Relationship between the Frequency of Link Words/Phrases and Manuscript Disposition among Manuscripts Submitted to a Journal?}

An all possible subsets canonical discriminant analysis was conducted to address this research question. Prior to conducting this analysis, Box's $M$ test was conducted to assess the homogeneity of the variance-covariance matrix involving the 12 variables of interest (Tabachnick \& Fidell, 2007). Box's $M$ statistic was 20.02, which suggested some heterogeneity of the variance-covariance matrix $(F[6,32641.69]=3.17, p=.80)$. Thus, caution should be exercised in interpreting the findings stemming from the discriminant analysis. Notwithstanding, the canonical discriminant analysis revealed that the following link words/phrases dimensions statistically significantly $\left(\times^{2}[3]=7.76, p<.05\right.$; Wilks's Lambda $=0.89)$ and practically significantly $\left(R_{c}=.33\right)$ predicted whether or not a manuscript was rejected by the editor: Add information/provide similarity (standardized canonical discriminant function coefficient $=.68$, structure coefficient $=.66$ ), Narration (standardized canonical discriminant function coefficient $=.38$, structure coefficient $=.31$ ), and Provide an 
emphasis (standardized canonical discriminant function coefficient $=.72$, structure coefficient $=.60$ ). More specifically, manuscripts that contained one or more link words/phrases that were classified as Add information/provide similarity were 1.75 (95\% confidence interval [CI] $=1.09,2.79$ ) times less likely to be rejected than were their counterparts, manuscripts that contained one or more link words/phrases that were classified as Narration were 1.32 (95\% $\mathrm{CI}=1.01,2.31)$ times less likely to be rejected than were their counterparts, and manuscripts that contained one or more link words/phrases that were classified as Provide an emphasis were $1.75(95 \% \mathrm{CI}=1.07,2.86)$ times less likely to be rejected than were their counterparts.

A comparison of the standardized and structure coefficients revealed no suppressor variables or multicollinearity because all the variables with significant standardized coefficients (i.e., > .30) also had significant structure coefficients (Henson, 2002; Onwuegbuzie \& Daniel, 2003). Interestingly, Provide an emphasis made the most noteworthy contribution in discriminating whether or not a manuscript is rejected, followed closely by Add information/provide similarity.

\subsection{Summary of the Results}

The summary of the findings pertaining to the five research questions are as follows:

$>$ The dimension labelled as Add information/provide similarity was the most commonly used, followed by the dimension labelled narration, and then followed by the dimension labelled sequence previous ideas.

$>$ The three most common link words, respectively, were Additionally, Finally, and Similarly.

Authors who use link words/phrases that can be classified as representing narration tended to make the least APA errors.

$>$ No link words/phrases dimension predicted the number of citation errors.

$>$ Manuscripts in which link words/phrases were used that can be classified as summarizing previous information tended to contain the most authors.

No link word/phrase dimension statistically significantly predicted either the gender of the first author or the genre of manuscript.

> Manuscripts that contained one or more link words/phrases that were classified as Add information/provide similarity were 1.75 times less likely to be rejected than were their counterparts.

$>$ Manuscripts that contained one or more link words/phrases that were classified as Narration were 1.32 times less likely to be rejected than were their counterparts.

Manuscripts that contained one or more link words/phrases that were classified as Provide an emphasis were 1.75 times less likely to be rejected than were their counterparts. 


\section{Discussion}

The present study is unique in at least four ways. First, it represents the only study in which the prevalence of the use of link words/phrases has been investigated. Second, it represents the first formal attempt to examine the link between the frequency of link words/phrases and style guide errors - namely, APA errors and citation errors - among manuscripts submitted to a journal. Third, this investigation represents the first study to investigate the relationship between the frequency of link words/phrases and select demographic characteristics (i.e., number of authors, gender of the lead author, genre of manuscript) among manuscripts submitted to a journal. Fourth, and most importantly, this study represents the first attempt to examine the relationship between the frequency of link words/phrases and manuscript disposition among manuscripts submitted to a journal.

The results from this current study demonstrate three unique findings in relation to the use of link words/phrases and manuscript preparation and submission. Specifically, the frequency of link words/phrases differ in relation to the following: (a) number of APA errors (i.e., narration), (b) number of authors (i.e., summarize previous information), and (c) adjudication decisions (i.e., Add information/provide similarity, Narration, and Provide an emphasis). The first relationship suggests that authors who minimally or do not use link words/phrases associated with narration also are those who commit the most APA errors, thereby suggesting that these authors' lack of writing discipline is multidimensional. The second relationship - that the more authors involved in writing the manuscript, the more likely they are to use link words/phrases associated with summarizing previous information-has intuitive appeal because it suggests that different authors writing different sections of a manuscript necessitates using words and phrases to link these different sections.

Clearly, the most notable finding is that manuscripts that exhibit greater use of link words/phrases associated with Add information/provide similarity, Narration, and Provide an emphasis draw more favorable reviews, and are more likely to be accepted for publication, than are manuscripts with less use. Although purely speculative, as an editor and reviewer, I contend that a plausible explanation resides in the complexity of scholarly articles - regardless of genre (i.e., quantitative research, qualitative research, mixed research). Because of this complexity, it is important for authors to use link words/phrases in a way that they provide appropriate transitions between sentences and between paragraphs - which serve as proxies for assumptions, ideas, beliefs, propositions, theories, schemas, models, hypotheses, and the like. This use of link words/phrases - especially those associated with Add information/provide similarity, Narration, and Provide an emphasis - then, maximize the coherence of a manuscript, which, in turn, make it easier for readers in general and journal reviewers in particular to follow the author's logic of argumentation. Based on the present findings, it appears that when a manuscript contains a sufficient number of link words/phrases, it is well received by consumers. However, of course, because these findings are correlational, follow-up studies are needed, optimally using mixed research techniques (see, for e.g., Johnson \& Onwuegbuzie, 2004; Johnson, Onwuegbuzie, \& Turner, 2007; Onwuegbuzie \& Leech, 2006; Onwuegbuzie \& Teddlie, 2003; Tashakkori \& Teddlie, 2010), to explore the causal nature of this relationship between the use of link words and quality of 
manuscript.

\section{References}

American Psychological Association. (2010). Publication manual of the American Psychological Association (6th ed.). Washington, DC: Author.

Cohen, J. (1988). Statistical power analysis for the behavioral sciences (2nd ed.). Hillsdale, NJ: Lawrence Erlbaum.

Frels, R. K., Onwuegbuzie, A. J., \& Slate, J. R. (2010). Editorial: A step-by-step guide for creating tables. Research in the Schools, 17(2), xxxviii-lix. Retrieved from http://www.msera.org/download/RITS_17_2_Tables.pdf

Hahs-Vaughn, D. L., Onwuegbuzie, A. J., Slate, J. R., \& Frels, R. K. (2009). Editorial: Bridging research-to-practice: Enhancing knowledge through abstracts. Research in the Schools, 16(2), xxxvii-xlv. Retrieved from http://www.msera.org/download/RITS_16_2_ Abstracts.pdf

Henson, R. K. (2002, April). The logic and interpretation of structure coefficients in multivariate general linear model analyses. Paper presented at the annual meeting of the American Educational Research Association, New Orleans, LA.

Johnson, R. B., \& Onwuegbuzie, A. J. (2004). Mixed methods research: A research paradigm whose time has come. Educational Researcher, 33(7), 14-26. https://doi.org/10.3102/001318 9X033007014

Johnson, R. B., Onwuegbuzie, A. J., \& Turner, L. A. (2007). Toward a definition of mixed methods research. Journal of Mixed Methods Research, 1, 112-133. https://doi.org/10.1177/ 1558689806298224

Myers, R. H. (1986). Classical and modern regression with applications. Boston, MA: Duxbury Press.

Onwuegbuzie, A. J., Combs, J. P., Frels, R. K., \& Slate, J. R. (2011). Editorial: Citation errors revisited: The case for Educational Researcher. Research in the Schools, 18(1), i-xxxv. Retrieved from http://www.msera.org/download/RITS_18_1_Complete.pdf

Onwuegbuzie, A. J., Combs, J. P., Slate, J. R., \& Frels, R. K. (2010). Editorial: Evidence-based guidelines for avoiding the most common APA errors in journal article submissions. Research in the Schools, 16(2), ix-xxxvi. Retrieved from http://msera.org/ download/RITS_16_2_APAErrors6th.pdf

Onwuegbuzie, A. J., \& Daniel, L. G. (February 12, 2003). Typology of analytical and interpretational errors in quantitative and qualitative educational research. Current Issues in Education, 6(2). Retrieved from http://cie.asu.edu/ojs/index.php/cieatasu/article/view/1609/0

Onwuegbuzie, A. J., \& Frels, R. K. (2016). Seven steps to a comprehensive literature review: A multimodal and cultural approach. London, England: Sage. 


\section{Macrothink}

Onwuegbuzie, A. J., Frels, R. K., \& Slate, J. R. (2010). Editorial: Evidence-based guidelines for avoiding the most prevalent and serious APA error in journal article submissions-The citation error. Research in the Schools, 17(2), i-xxiv. Retrieved from http://www.msera.org/ download/RITS_17_2_Citations.pdf

Onwuegbuzie, A. J., Hwang, E., Combs, J. C., \& Slate, J. R. (2012). Editorial: Evidence-based guidelines for avoiding reference list errors in manuscripts submitted to journals for review for publication: A replication case study of Educational Researcher. Research in the Schools, 19(2), i-xvi.

Onwuegbuzie, A. J., Hwang, E., Frels, R. K., \& Slate, J. R. (2011). Editorial: Evidence-based guidelines for avoiding reference list errors in manuscripts submitted to journals for review for publication. Research in the Schools, 18(2), i-xli. Retrieved from http://msera.org/rits.htm

Onwuegbuzie, A. J., \& Leech, N. L. (2006). Linking research questions to mixed methods data analysis procedures. The Qualitative Report, 11, 474-498. Retrieved from http://www.nova.edu/ssss/QR/QR11 3/Onwuegbuzie.pdf

Onwuegbuzie, A. J., Mallette, M. H., Hwang, E., \& Slate, J. R. (2013). Editorial: Evidence-based guidelines for avoiding poor readability in manuscripts submitted to journals for review for publication. Research in the Schools, 20(1), i-xi.

Onwuegbuzie, A. J., \& Teddlie, C. (2003). A framework for analyzing data in mixed methods research. In A. Tashakkori \& C. Teddlie (Eds.), Handbook of mixed methods in social and behavioral research (pp. 351-383). Thousand Oaks, CA: Sage.

Provalis Research. (2014a). QDA Miner (Version 4.1.12) [Computer software]. Montreal, Quebec, Canada: Author.

Provalis Research. (2014b). WordStat (Version 6.1.23) [Computer software]. Montreal, Quebec, Canada: Author.

Tabachnick, B. G., \& Fidell, L. S. (2007). Using multivariate statistics (5th ed.). Boston, MA: Allyn \& Bacon.

Tashakkori, A., \& Teddlie, C. (Eds.). (2010). Sage handbook of mixed methods in social and behavioral research (2nd ed.). Thousand Oaks, CA: Sage. https://doi.org/10.4135/9781506 335193

Thompson, B. (1995). Stepwise regression and stepwise discriminant analysis need not apply here: A guidelines editorial. Educational and Psychological Measurement, 55, 525-534. https://doi.org/10.1177/0013164495055004001 


\section{Copyright Disclaimer}

Copyright for this article is retained by the author(s), with first publication rights granted to the journal.

This is an open-access article distributed under the terms and conditions of the Creative Commons Attribution license (http://creativecommons.org/licenses/by/3.0/). 